\title{
GLACIER MONITORING INTERNSHIP REPORT: Grand Teton National PaRk, 2015
}

\author{
EMILY BAKER \\ UNIVERSITY OF COLORADO-BOULDER $\uparrow$ BOULDER, CO
}

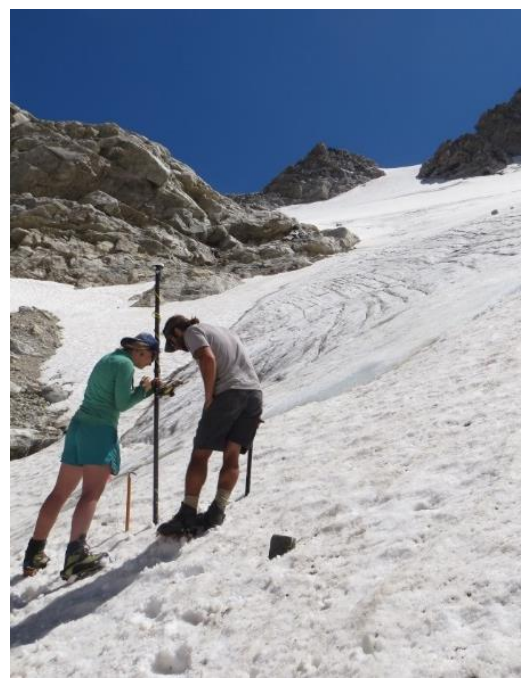

\section{$\downarrow$ BACKGROUND}

The small glaciers of Grand Teton National Park (GTNP) are iconic landmarks, enhancing the experience of millions of visitors to the park each year. They are valuable far beyond their beauty, and play a critical role in the park's unique high-elevation ecosystems.

Glaciers act as water towers of the mountain ecosystem, storing winter precipitation as ice which can be utilized slowly over the summer months, as it slowly melts to become runoff. Glacial melt controls stream temperatures, enhances late-season streamflow volumes, and is a critical input for many highelevation plant and animal communities. Additionally, change in glacier volume serves as a multi-year record of climate, and gives a stark illustration of how climate is changing. A series of high-snow winters and cloudy, cool summer years cause glaciers to grow, while lowsnow winters and clear, hot summer years cause glaciers to shrink. Changes in glacial extent and volume are good indicators of multi-year climate trends.

Recent studies of glacial extents in GTNP show significant and rapid retreat of glaciers in all areas. On-the-ground estimates of glacier volume, yearly volume changes and glacial motion are not yet studied; this research aims to fill this gap. Here, we detail the development of a simple mass-balance (overall ice melt or accumulation) monitoring protocol for reference glaciers in GTNP, using readily available equipment currently owned by GNTP, which can be performed in-house, with existing NPS expertise and equipment. 


\section{$\downarrow$ MEASUREMENT OBJECTIVES}

- Glacier Size

- What is the volume of the glacier?

- What is the surface area of glacier?

\section{- Change in Volume}

○ How much did the glacier grow or melt, since last measured?

- Why: summer temperatures, date of snow melt-off, or incoming sun (cloudiness)?

- Movement

$\circ \quad$ Is the glacier moving? If not, it is no longer technically a glacier, but stagnant ice.

- How far did it move?

- What time of year did it flow fastest?

\section{$\uparrow \quad$ TOOLS}

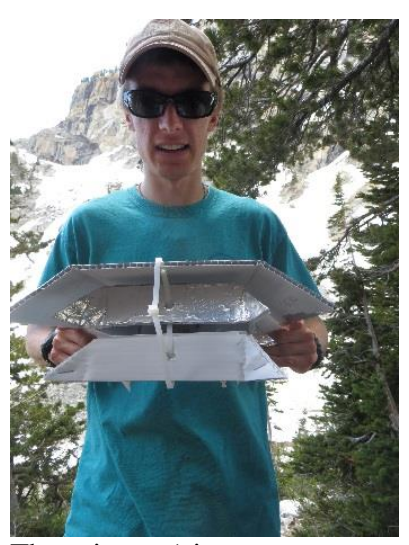

Thermistors (air temperature sensors)

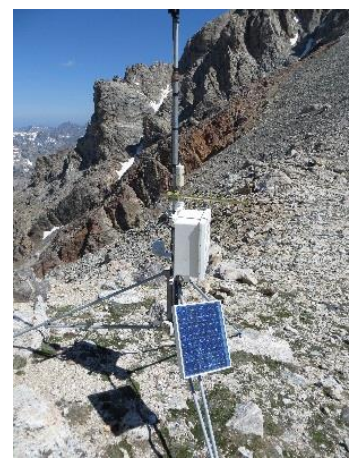

Pyranometer (solar radiation / sunlight energy sensor)

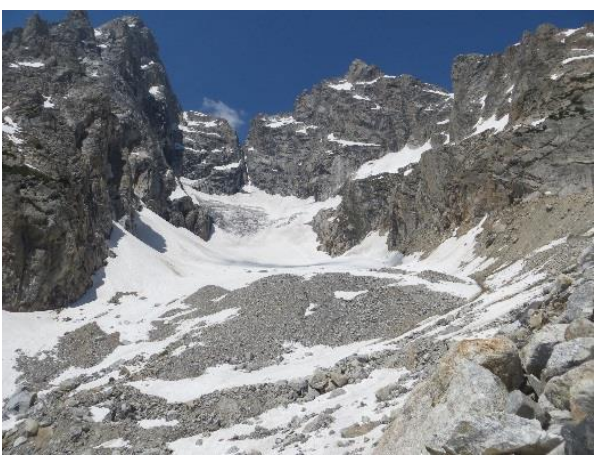

Repeat photo monitoring points

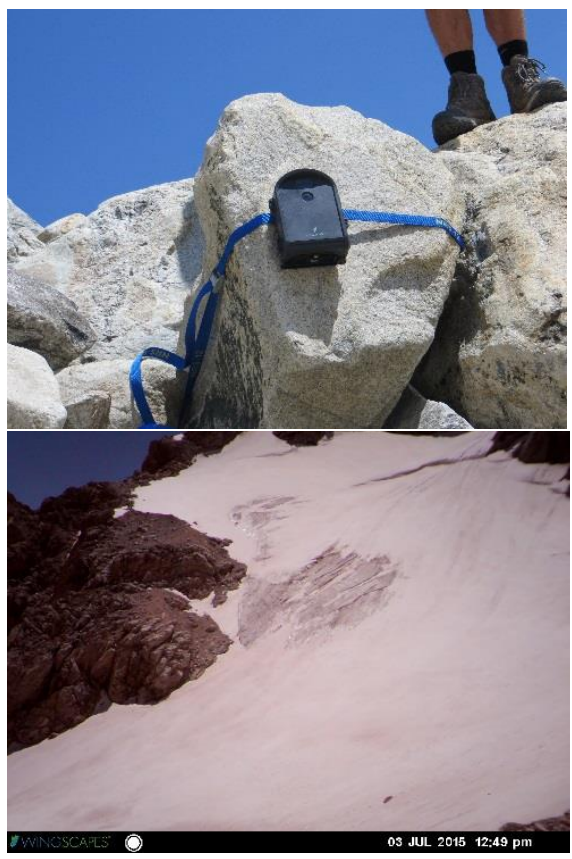

Time lapse cameras (daily photos) 


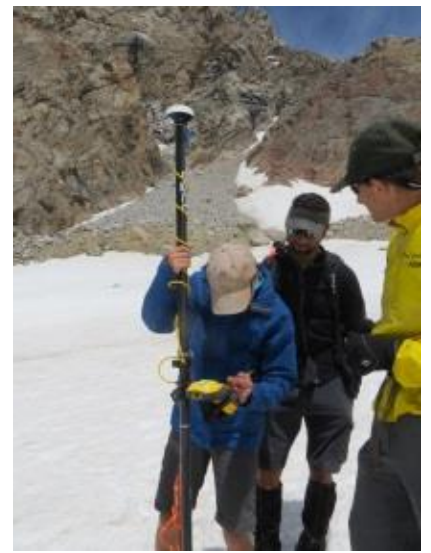

Mapping grade GPS: Geo X7

Energy Balance Melt Modeling

$$
M=\left\{\begin{array}{cc}
{[T F+S R F(1-\alpha) G] T} & \frac{T>T t}{T<T t} \\
0 &
\end{array}\right.
$$

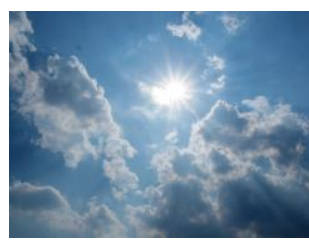

Sun
Vs.

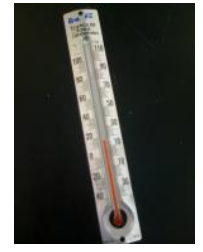

Air Temperature

\section{$\uparrow \quad$ METHODS}

\section{Glacier areal extent}

Glacier area can be mapped in three ways: using remotely sensed aerial imagery (i.e., satellite, or airplane), using orthorectified ground-based photography (i.e., repeat photo monitoring points), or directly mapping glacier margins with a GPS unit. Recent research has used available historical aerial photography (Reynolds 2012, Tootle 2010) but reported difficulties distinguishing ice from snow, and remained unable to correlate change in glacier area with available climate forcings (PRISM). Our deployment of high-elevation, glacier-adjacent temperature sensors and pyranometer will allow for partitioning of observed melt into that caused by higher air temperatures vs. incoming shortwave solar radiation, and additionally allow for re-analysis of PRISM data, with the potential of using enhanced PRISM to review and improve this earlier work on historical glacial area change.

Change in glacier area can be analyzed as frequently as data are available: either whenever lateseason (early September) aerial imagery is flown; yearly, based upon field photo-monitoring points; or yearly, based upon field-surveyed GPS glacial margins.

\section{Glacier volume and volume change}

Surface elevations on reference glaciers will be taken with a GPS survey on an annual basis, or multi-year basis, as GIS and Climbing Ranger staff time allows. A high density of points collected on the glacier surface allows for computation of a complete, interpolated glacier surface elevation. Comparison of this surface from year-to-year allows for calculation of change in volume.

Absolute volume of the glacier can be determined with use of a Ground Penetrating Radar unit, which maps the depth to bedrock underneath the ice. Cooperation with partners at the University of Colorado is pending to use a GPR unit in the Fall 2015 survey of Middle Teton Glacier, and thus map the bedrock and measure true glacier volume. Bedrock needs to be mapped only once with a GPR; subsequent years with different ice surfaces will still have the same underlying bedrock surface. Ideally, a GPR survey would be completed at each glacier of interest, for knowledge of true remaining ice volume. However, estimates of ice volume change are not affected by knowing absolute size of the glacier. Rather, knowledge of absolute volume allows for better estimates of glacial longevity (i.e., how long it will likely survive, under current or projected climate conditions). Melt rates and ice volume are the two key variables needed to estimate how long a glacier will survive.

\section{Glacier movement}

A glacier is defined by its motion; a glacier which is no longer flowing is technically a body of stagnant ice (also known as perennial snow and ice), and no longer a glacier. Recent studies on GTNP glaciers have focused on aerial extent, and not motion. We do not currently know how fast the glaciers are flowing, or even if flow is occurring at all. This is especially true of rock-covered glaciers (Petersen) and portions of glaciers which are rock covered (lower lobe of the Middle Teton Glacier), where crevasses (also an indicator of recent motion) cannot be observed. Motion will be quantified using time lapse 
photography. Moultrie brand time-lapse cameras have been deployed at glaciers of interest, during the summer of 2015, at stable locations, allowing for continuous monitoring of the glacier from a static point. The cameras are programmed to take three daily photos, which should yield at least one per day where clouds do not obscure the field of view. Compiling daily images gives a time-lapse video of glacier motion and melting over the course of the summer including dates when snow melts from the surface of the glacier, and ice (as opposed to seasonal snow) begins melting. Measurement of two fixed points in image background, and distance from camera, will allow calculation of flow rates, using basic trigonometry.

Additionally, glacier movement will be measured directly using markers placed on the ice surface. Rocks wrapped with surveyor's tape were placed on the surface of the Middle Teton Glacier on July 2, 2015, and their location measured with the mapping grade GPS unit. Measuring the location of these fixed points on the glacier's surface will allow calculation of annual flow at 3 fixed points along its surface, and provide a check on the accuracy of photoderived estimates of motion. Depending on the frequency of surface marker re-visitation, sub-annual measurement of flow rate can be calculated, approximate timing of maximum flow rate can be determined, and potentially correlated with climate variables (solar radiation and air temperature). High flow rates are known to coincide with times where more melt is present at the glacier's bed surface, lubricating bedrock friction and speeding flow. Knowing timing of maximum flow rates would give information on the timing of maximum glacial melt. Otherwise, glacial melt volumes are measured only once per year, with information available on timing of maximum melt rates.

\section{Determining the cause of melt- Modified degree day modeling}

Multiple years of surface elevation measurements on index glaciers allows us to calculate changes in ice volumes. The first surface elevation survey was conducted on Schoolroom Glacier in summer 2014; the second will be conducted on Middle Teton Glacier in summer 2015. These surveys tell us what is happening to the index glaciers - are they growing, or shrinking? They do not, however, allow us to determine what caused that change. Was it an anomaly in snowfall (low/ high)? Was it an abnormally cloudy spring and summer, where sun melted only a small quantity of glacial ice? Was it a very hot summer, where temperature drove the melting, even if the summer was quite cloudy? We can answer these questions using two known inputs: incoming solar radiation (measured at the Lower Saddle \& Kelly Teton Science School pyranometers), and high-elevation air temperature (our adjacent thermistors). With these, we can construct a modified degree day glacier melt model. Academic researchers commonly apply full energy-balance models containing information on latent heat fluxes, longwave radiation, and surface albedo, but that work is beyond the scope of this project, mostly due to increased cost of instrumentation, and higher uncertainties associated with model parameterization (including estimates of surface roughness, surface emissivity, and other quantities that are difficult to measure accurately in the field).

Temperature-index models are widely used operationally, by NOAA and the USGS for snowmelt runoff forecasting. A modified degree day model allows for use of a temperature-indexed model, while incorporating information about incoming solar radiation and allowing us to partition melt into that caused primarily by higher temperatures from that caused by incoming sunlight energy. A modified degree day model has far lower data requirements than an energy-balance model, incorporates data on solar radiation - known to be the dominant source of melt energy on most glaciers - and has a stronger physical basis than simple temperature-only index models. Additionally, the inclusion of a solar input term has been shown to improve melt modeling substantially across varied ecosystems (e.g., Hock 1999, Pellicotti 2005).

This modeling portion of the project is under development in conjunction with collaborators at the Institute of Arctic and Alpine Research (INSTAAR) at the University of Colorado, and the North Cascades National Park Service Complex (NOCA). Its development will follow collection of data from summer 2015, and will take a form similar to

$$
M=\left\{\begin{array}{cc}
{[T F+S R F(1-\alpha) G] T} & \frac{T>T t}{T<T t} \\
0 &
\end{array}\right.
$$

where TF and SRF are empirical coefficients for temperature factor and shortwave radiation factor, $\mathrm{G}$ is incoming solar radiation, $\mathrm{M}$ is melt (in $\mathrm{mm} /$ day) and $\mathrm{Tt}$ is a temperature under which no melt will occur $\left(1^{\circ}\right.$ C, following Pellicotti 2005). Model development will follow Huintjes (2010), Pellicotti (2005), Hock (1999) and others who have applied degree-day melt modeling to small, alpine glaciers. Our model will be calibrated against sub-annual (approximately monthly) surface melt measurements made in summer 
2015 on the surface of Middle Teton Glacier. The calculated TF and SRF empirical coefficients can be assumed to be the same for other glaciers in the range, and allow potential extrapolation of melt modeling to all glaciers in the range, utilizing the $0.5 \mathrm{~m}$ Digital Elevation Model (DEM) derived from a 2014 LiDAR flight over GTNP. The melt model allows us to ask why the glaciers are melting - less snow, more sun, or higher temperatures - and additionally, gives us power to estimate melt on un-measured glaciers in the Tetons, such as Triple Glaciers, Falling Ice and Skillet, which remain unstudied largely due to access and safety issues. Until direct measurements can be made on these glaciers, modeling using adjacent glacial melt factors and site-specific, LiDAR-derived solar radiation information will allow us to make assessments of glacial volume change and higher confidence. Time-lapse cameras focused on these inaccessible glaciers will allow for a field-based check on modeling efforts.

\section{$\downarrow \quad$ Additional Products}

- Time-lapse videos of glacier motion, snowmelt, and alpine plant growth.

- Network of high-elevation temperature sensors: data useful for many applications.

- Increasing citizen science and engagement with climate and hydrology resource issues, through recruitment of public for repeat glacier photo points.

- Repeat and time-lapse photography at multiple high-altitude locations: useful for plant phenology and flower timing.

\section{$\downarrow \quad$ Literature Cited}

Hock, R. 1999. Distributed temperature-index ice- and snowmelt model including potential direct solar radiation, J. Glaciol. 45(149):101-111.

Pellicciotti, F., B. Brock, U. Strasser, P. Burlando, M. Funk, and J. Corripio. 2005. An enhanced temperature-index glacier melt model including the shortwave radiation balance: Development and testing for Haut Glacier d'Arolla, Switzerland, J. Glaciol. 51(175):573-587.

Reynolds, H. 2012. Recent Glacier Fluctuations in Grand Teton National Park, Wyoming. Master's Thesis.

Tootle, K.. 2010. Glacial Change in Grand Teton National Park. Master's Thesis. 